\title{
Health records as the basis of clinical coding: Is the quality adequate? A qualitative study of medical coders' perceptions
}

\author{
Vera Alonso, MSc (1) ${ }^{1,2}$, \\ João Vasco Santos, $M D^{1,2,3}$, \\ Marta Pinto, $P h D^{2,4,5}$, \\ Joana Ferreira, $M \mathrm{SC}^{1,2}$, \\ Isabel Lema, $B S c^{1,2}$, \\ Fernando Lopes, $M D^{1,2}$, \\ Alberto Freitas, $P h D$ (1) 1,2
}

\begin{abstract}
Background: Health records are the basis of clinical coding. In Portugal, relevant diagnoses and procedures are abstracted and categorised using an internationally accepted classification system and the resulting codes, together with the administrative data, are then grouped into diagnosis-related groups (DRGs). Hospital reimbursement is partially calculated from the DRGs. Moreover, the administrative database generated with these data is widely used in research and epidemiology, among other purposes. Objective: To explore the perceptions of medical coders (medical doctors) regarding possible problems with health records that may affect the quality of coded data. Method: A qualitative design using four focus groups sessions with 10 medical coders was undertaken between October and November 2017. The convenience sample was obtained from four public hospitals in Portugal. Questions related to problems with the coding process were developed from the literature and authors' expertise. The focus groups sessions were taped, transcribed and analysed to elicit themes. Results: There are several problems, identified by the focus groups, in health records that influence the coded data: the lack of or unclear documented information; the variability in diagnosis description; "copy \& paste"; and the lack of solutions to solve these problems. Conclusion and implications: The use of standards in health records, audits and physician awareness could increase the quality of health records, contributing to improvements in the quality of coded data, and in the fulfilment of its purposes (e.g. more accurate payments and more reliable research).
\end{abstract}

\section{Keywords (MeSH)}

clinical coding; International Classification of Diseases; medical records; data quality; health information management; diagnosis-related groups

\section{Supplementary keywords}

data accuracy; qualitative research; focus groups

\section{Introduction}

Health records, both electronic and paper based, represent a source of information about the patient's health status, diseases, disease progression, procedures, treatment effectiveness and quality of healthcare (Ayatollahi et al., 2014; Miller and Sim, 2004). In Portugal, both types of health records coexist. Health records are not just meant for clinical purposes. The information contained in the records from inpatients and outpatients is systematically abstracted, coded and grouped into diagnosis-related groups, generating an administrative database used for reimbursement and further reused for research (Freitas

\footnotetext{
' Department of Community Medicine, Information and Health Decision Sciences (MEDCIDS), Faculty of Medicine, University of Porto, Porto, Portugal

${ }^{2}$ CINTESIS - Centre for Health Technology and Services Research, Porto, Portugal

${ }^{3}$ Public Health Unit, ACES Grande Porto VIII - Espinho/Gaia, Vila Nova de Gaia, Portugal

${ }^{4}$ Faculty of Psychology and Education Sciences, University of Porto, Porto, Portugal

${ }^{5}$ Subgroup of Terrorism and Security of the Crime and Justice Group of Campbell Collaboration, University of Queensland, Australia
}

Accepted for publication December 15, 2018.

Corresponding author:

Vera Alonso, Department of Community Medicine, Information and Health Decision Sciences (MEDCIDS), Faculty of Medicine, University of Porto, Rua Dr. Plácido da Costa, Porto 4200-450, Portugal.

E-mail: vera.alonsop@gmail.com 
et al., 2012; Pinho et al., 2015; Santos et al., 2016, 2017; Sousa-Pinto et al., 2018).

Clinical coding is the process of transforming the information about diseases or procedures recorded in the health records into numeric or alphanumeric codes, that is, it categorises health records information (Tatham, 2008). In Portugal, the International Classification of Diseases - Ninth Revision - Clinical Modification (ICD-9-CM) was used until the end of 2016 when the International Classification of Diseases - Tenth Revision - Clinical Modification/Procedure Classification System (ICD-10-CM/PCS) was introduced. Unlike some other countries, the Portuguese medical coders are medical doctors. They are trained at the Escola Nacional de Saúde Pública - National School of Public Health, through a course conducted in partnership with the Administração Central do Sistema de Saúde (ACSS) - Health System Central Administration. For continual training, three annual training actions (one in the north, one in the centre and one in the south of the country) are carried out by Associação dos Médicos Auditores e Codificadores Clinicos (AMACC) - Association of Clinical Coding and Auditing Physicians - and monthly seminars are organised by the Department of Community Medicine, Information and Health Decision Sciences (MEDCIDS), at the Faculty of Medicine of the University of Porto.

Health records are the basis of clinical coding. Hence, the quality of documented information affects the quality of coded data. If the documentation of healthcare is poor, the assigned clinical codes will not be the most appropriate (Southern et al., 2016). The specificity of the information recorded is also an important factor in clinical coding, that is, for the coding to be performed with the maximum accuracy, the necessary information should all be present in the health records (DeAlmeida et al., 2014; Kurusz, 2015; Santos et al., 2008). Variations in the description of diagnosis by clinicians, lack of clarity in records, lack of legibility, incomplete documentation, use of synonyms and abbreviations and lack of communication between health professionals and medical coders are hindrances to good clinical coding (Farzandipour et al., 2010; McKenzie et al., 2004; O’Malley et al., 2005; Santos et al., 2008; Tang et al., 2017). All of these problems contribute to the lack of data quality in health records.

The aim of this exploratory study was to investigate the perceptions of medical coders regarding possible problems with health records that may affect the quality of the coded data.

\section{Methods}

Data analysis and reporting were conducted in accordance with the Consolidated Criteria for Reporting Qualitative Research (COREQ) guidelines (Tong et al., 2007) (see Appendix 1).

\section{Research design}

We conducted four focus group sessions, in October and November 2017, to ascertain medical coders' perceptions of coding problems, including problems with health records, which may impact coding quality.

\section{Sample}

Convenience samples of medical coders were involved in this study. Contact details were obtained through participation in meetings and through researchers' contact lists, which allowed the collection of 54 medical coders' email addresses from four public hospitals. These four hospitals represent an accessible sample of the 105 existing hospitals, including public and those in public-private partnerships (INE, 2017). The four hospitals were from three different cities. The only inclusion criterion for study participation was to have had experience in clinical coding.

Medical coders were invited by email to complete a short questionnaire about their demographic characteristics, experience in clinical coding and availability to participate in a focus group. Twenty-one replies were received and a new email was then sent to these participants in order to determine the most suitable date for conducting the focus groups. Eleven medical coders, belonging to the four hospitals, showed interest in participating. A third email was sent to inform each participant about the date of the focus group session and, 3 days before the session, another reminder was sent by email. One of the eleven medical coders was not able to attend any of the sessions.

\section{Data collection}

The interview guide was developed based on problems already identified in the scientific literature (Bajaj et al., 2007; DeAlmeida et al., 2014; Farzandipour et al., 2010; Haghighi et al., 2014; Lucyk et al., 2017; O’Malley et al., 2005; Tang et al., 2017) and on the researchers' expertise (questions concerning health records in Box 1). During the sessions, an interview guide was followed, but other issues arose. The focus group sessions were held in the Faculty of Medicine of the University of Porto, Portugal. The duration of the focus groups sessions ranged from 1 hour and $15 \mathrm{~min}$ utes to 1 hour and 50 minutes. Before starting the sessions, all participants received written and oral information about the study and signed an informed consent document allowing the recording and use of data, as well as were assured of the anonymity and confidentiality of the collected data. The four focus groups were conducted with two groups of five medical coders. Each group was submitted to two different interview guides, with different questions. In one session in each group there was a participant who was unable to attend.

\section{Data analysis}

Sessions were recorded on audio files with a mobile phone, using the Dictaphone software. Microsoft Word was used to transcribe all the recordings. A clean transcript was produced: repetitions, false starts and possible errors were removed from the text to become clearer and friendlier for the reader. Recordings were deleted after that process. Through thematic content analysis, all the information 


\section{Box I. Focus group questions (concerning health records)}

I. Health records are the basis of clinical coding; how do you classify their quality?

2. What questions related to health records may affect the quality of clinical coding?

3. How do you think the quality of health records could be improved?

4. Is there any relation between the involvement of all health professionals in the coding process and the quality of the coded data? If so, which one? If not, why?

5 . What is your opinion about the abbreviations used?

6. Is there any relation between the variations in the descriptions of the diagnoses made by health professionals and the quality of the coded data? If so, which one? If not, why?

7. Regarding access to the health records for coding, how do you quantify the degree of difficulty?

discussed was grouped by themes and subthemes related to the aims of the study (Bardin, 2011). Results were analysed by the authors. One author grouped the information and these data were subsequently validated by consensus with the other authors.

\section{Results}

Ten medical coders participated in the focus groups. Most of the participants were female ( 8 of 10$)$ and worked parttime in clinical coding ( 7 of 10). The median age was 55 years $(\mathrm{SD}=12$ years) and the median coding experience was 9 years (range $=0.5-28$ years) $($ See Table 1$)$.

Four themes emerged from factors raised by medical coders as influencing health records' quality and, consequently, the quality of coded data: (i) incomplete/unclear documentation in health records [incomplete/missing discharge note (document with a discharge summary); incomplete/missing surgical report; use of abbreviations and acronyms]; (ii) variability in health records (variations in diagnosis description by different health professionals); (iii) paper health records (PHRs) and electronic health records (EHRs) (access to EHRs); and (iv) possible solutions to problems with health records (health records standards; health records audits). For each result, one or more examples from the focus group have been presented, with a code assigned to each participant and hospital at the end of the quotations in brackets.

\section{Incomplete/unclear documentation in health records}

Participants stated that the absence of any element of the record and the lack of organisation were the main obstacles to good coding: "There is no good coding, neither good nor bad, that is to say, there is no full coding if there is no correct and complete health record of the episode, whether of hospitalisation or whatever" (Participant 7 (P7), Hospital 2 (H2)); "There are services that record discharge notes in
Table I. Characteristics of the focus groups' participants $(n=10)$.

\begin{tabular}{lll}
\hline Characteristics & & $n$ \\
\hline Age (years) & $30-39$ & 1 \\
& $40-49$ & 2 \\
& $50-59$ & 4 \\
Experience in clinical coding (years) & $>59$ & 3 \\
& $<1$ & 1 \\
& $1-5$ & 2 \\
& $6-9$ & 4 \\
Gender & $10-19$ & 1 \\
& $>19$ & 2 \\
Work modality (clinical coding) & Female & 8 \\
& Male & 2 \\
& Full-time & 3 \\
\hline
\end{tabular}

various locations... and we have to open a lot of directories, and sometimes we do not find them [the discharge notes]" (P5, H1). Participants also identified the anaesthesia report, the surgical report, the admission and discharge notes, the pathology report and the nursing records as being the most important documents for coding: "What is standard now is that the admission and the discharge notes, the progress notes, the surgical report, the pathology report, the anaesthesia report and some nursing records, with the bedsores, all this is already included...however, even so, we are having difficulties" (P7, H2). However, as discussed in the following subthemes, these important documents were not consistently present in all records.

Incomplete/missing discharge note. Although the discharge note is a document required by law, participants stated that "there are services that do not fill a discharge note yet" (P2, H1). Its existence varies with specialty and hospital: "Discharge notes, in general, are good" (P1, H3); "Sometimes they don't exist. Physicians only write daily progress notes" (P4, H1); "In outpatient surgery episodes, discharge notes rarely exist, and this also causes lack of information" (P10, H1). Additionally, it was discussed that in some services, there are quite extensive notes, in which exams are transcribed but diagnosis may not be specified: "What I find worse are discharge notes; I think most people don't know what a discharge note is. Either they transcribe exams in full, ... and sometimes when we get to the end of the record, after reading it all, they don't state a diagnosis for us to code" (P5, H1); "There are two extremes: some are very exhaustive discharge notes, and others are descriptive but, often, not even affirmative in relation to diagnosis, with several things being left out. It is very difficult to assume them" (P8, H2). The discharge note was more often missing when patients died, or, there was a lack of completeness; often the record did not have a summary of the hospitalisation in order to abstract and code. This might have happened because the physician who wrote the discharge note may not have been the same physician who was responsible for the patient during hospitalisation. "Death notes almost do not exist" (P2, H1); "some days ago, I 
received a death note about a patient hospitalised for three months, with three lines ... This was on the admission note; [the doctor] wrote the pathologies and then said 'was admitted, something has gone wrong and died"' (P5, H1).

Incomplete/missing surgical report. In general, participants stated that there were, on occasions, no surgical reports, or they lacked completeness, which influenced coding. Once again, this seemed to vary from specialty to specialty. "We have no complete information in the surgical report, what was done to the patient, the patients problems. This is the greatest difficulty" (P6, H1); "And they do not write the surgical report" (P2, H1); " (. . ) their surgical descriptions are good" (P5, H1), [referring to thoracic surgery]. In addition, one of the participants argued that the surgeon "is not defending himself, he is not defending the patient and he is prejudicing the hospital" (P7, H2), when the surgical report is absent or lacks completeness.

Use of abbreviations and acronyms. It was widely agreed that the use of acronyms and abbreviations was another negative aspect in health records, and that health professionals should not use them. Sometimes, physicians use acronyms that medical coders are not familiar with, which makes coding more difficult. For example, "FCP? In an obstetric record? I could not understand that it meant Ferida Corrigida no Períneo (Perineum Laceration Repair)" (P9, H1); "I am against abbreviations. I've always been. People have to write things ( . . )" (P2, H1); "Regarding abbreviations it is very difficult [to understand and code the records]." (P6, H1). One participant stated that the problem in coding abbreviations was the medical coder "thinking that it is one thing and, after all, it is another" (P3, H4), concluding that in this situation "it is better not to code if we are not sure" (P3, H4). Two other participants agreed with this statement (P2, H1; P4, H1).

\section{Variability in health records}

The quality of health records is affected by great variability in content, depending on the hospital, the specialty or, even, the professional: "Some [records] are bad, others are excessive, others have lack of information; I think there is no middle way" (P5, H1); "It depends on the provider" (P2, and (similar comment by) P5, H1); "I think it is different from hospital to hospital" (P8, H2); "and above all we also find that it is different, depending on the specialty of the episodes of care we are coding" (P6, H1). When questioned about the evolution of the quality of health records, even though the great majority affirmed that quality is improving, one of the participants disagreed: "But there is a positive evolution, no doubt" (P1, H3); "Actually, it is improving" (P2, H1); "But I think the tendency is to get worse" (P5, H1).

Variations in diagnosis description by different health professionals. Some participants agreed that there was variability in diagnosis description, relating this to the assertiveness of medical doctors. Moreover, this lack of assertiveness/confidence could result in the lack of specificity. They also attributed these problems to the transcription of exams' results instead of interpreting them. "This is about the specificity of diagnosis" (P1, H3 and (similar comment by) P4, H1); "In [internal] medicine, there are colleagues who always document pneumonia, pseudomonas pneumonia... and others always document [only] respiratory infection. There are people who do not like to commit themselves with a diagnosis ... and that depends on the doctor; there are doctors more assertive who clearly state the disease..." (P2, H1); "Sometimes, physicians write: aspiration pneumonia / nosocomial pneumonia/ tracheobronchitis" (P5, H1); "Often, the diagnosis is not written. For example, for some physicians it seems to be difficult to assume a sepsis by an E. Coli, and they do not specify the final diagnosis [specific infection or sepsis]" (P8, H2); "Computerised tomography refers to 'abdominal collections', and medical doctors only transcribe this finding [not the diagnosis, possibly an abscess]" (P5, H1).

\section{PHRs compared to EHRs}

All participants stated that they preferred EHRs because they did not have to "decipher doctors' handwriting" and because the EHR is more "standardised": "Doctor's handwriting. Absolutely. That is a fantastic advantage. For those who [have] code[d] for many years, it is a significant difference" (P2, H1). However, the impossibility of making explanatory drawings that could help in the surgical areas and "copy \& paste" were problems associated with EHRs. "Copy \& paste" is the origin of large transcriptions to the records without relevant information and leading to repeating errors from the first to the last daily progress note, complicating and slowing coding. "I think that [explanatory drawings] would help me in the thoracic surgery. If they would draw the exact schema, instead of making me dream up what they are doing ... I would see it sooner" (P2, $\mathrm{H1}$ ); "When there is 'copy \& paste' of previous records, we begin to read, begin to code, and when we get to the end, (...), we sometimes realise that it was not new [but referred to a previous episode of care]" (P3, H4); "And if there's something wrong in a progress note, the error continues [being copied] up to the end" $(\mathrm{P} 2, \mathrm{H} 1)$.

Access to EHRs. In general, participants indicated no difficulty in accessing EHRs: "and because we are lucky, as I work in Hospital 2, I have access to all clinical information" (P8, H2). However, there may be also some difficulties in the access to some record's documents, since a medical coder from one of those hospitals gave opposing information: "and we also do not have access to the anaesthesia sheet, that is, it is not annexed" (P6, H1); "It is all right there" (P9, H1).

\section{Possible solutions to problems with health records}

One of the participants reported how his/her hospital was trying to solve the problem of no existing discharge notes. According to the participant, the adopted measure fulfilled 
its purpose (i.e. increase the number of discharge notes). "Presentation of discharge notes, sometimes, dragged on, I do not know for how long, ... regardless of that, there were delays in presenting discharge notes ... and today the computer system on the eighth day after discharge automatically closes [and blocks] the record" (P7, H2). Concerning the problem of using abbreviations and acronyms, another participant presented a possible solution already implemented in his/her hospital: "[We made] a list of abbreviations that were the official ones. If they were in that list, they could be used. It did not mean that people had to use them" (P3, H4). Another participant did not agree with this method and argued that it would not solve the problem: "then transfer the patient with these abbreviations to another hospital that does not know your list and everything is wrong in it" (P5, H1).

Some of the participants presented Google and Portal da Codificação (platform to support the activity of medical coders in Portugal) as resources to consult the meaning of some abbreviations and acronyms. One participant argued that these resources were useless when the abbreviations "are invented by the writer" (P5, H1). "Of course we can go to Google all the time and Google will tell us" (P6, H1); "( ... I I consult [Portal da Codificação]” (P3, H4). Two participants suggested that health professionals and services should be penalised for lack of quality of health records. Some participants argued that health professionals and institutions did not care about records and did not acknowledge their own errors, and others argued that they were growingly concerned about having better records. " (... ) and then the service would be penalised monetarily. Because people would then be more careful" (P5, H1); "People are too busy, and they do not want to have time to do it, and forget records" (P9, H1); "There is an effort, I think, at least I speak of my hospital, to have more complete records" (P1, H3). However, they argued that no great change would come from medical coders or health professionals; it must start from the entities with authority: "I think it can't be the medical coder to speak, I think it must be something that comes from above" (P9, H1).

Health records standards. Participants stated that health records' standardisation would solve some of the problems. Participants highlighted the importance of using the SOAP note (acronym for Subjective, Objective, Assessment, and Plan, which structure medical documentation) and stated that standardisation was not only important for clinical coding but also for providing care. "If there was a standard, a discharge note in an application, a standardised discharge note... maybe in the future it will be very important" (P7, $\mathrm{H} 2$ ); "Everything that follows a rule is easier for us to follow rather than each one proceeding in his/her own way" (P3, H4); "When I am called to a medical service to see a patient..., while I spend time reading diaries the patient may die; if otherwise I go directly to the patient I may lose important information about the patient's current event...the presence of a daily opinion of the doctor responsible for the patient, in the section A of SOAP, would facilitate patient care" (P5, H1).
Health records audits. Participants reported that, in the past, there had been internal reviews of health records, mainly with an educational purpose towards improved health records. One participant highlighted the need of relevant information for health records audits, particularly for clearly defined audit processes, as well as widely accepted official guidelines to standardise health records. "Always had an internal audit, someone to see, at least, the discharge note, review it and see if it was well done" (P3, H4); "At this time, we are trying again; we are going to do some audits of health records, we do not have many parameters (...); we also haven't got official guidelines to standardise health records" (P9, H1).

\section{Discussion}

It is widely believed that health records and their quality have great importance, not only for the medical coding activity but also for further uses of the databases generated by the coded data (e.g. research). However, in order to achieve these purposes fully, complete health records with high data quality is essential. In this focus group study, we identified several problems recognised by Portuguese medical coders, such as the lack of information in the documents (e.g. discharge note, surgical report), unclear documentation (e.g. use of abbreviations or acronyms), variability in health records (e.g. variations in diagnosis description) and the lack of solutions for these problems (e.g. lack of guidelines, decrease in health records audits).

\section{Incomplete/unclear documentation in health records}

It is known that the quality of the coded data is compromised when health records do not have sufficient quality (DeAlmeida et al., 2014; Kurusz, 2015; Santos et al., 2008; Southern et al., 2016), which was corroborated by the medical coders participating in this study. In addition to the problem of health record quality, participants mentioned that sometimes there was a lack of information in certain elements of the record, such as the discharge note, the most important document for coding.

While the basic information required in the discharge note has already been established (Diário da República, 2013), lack of information in the discharge note continued to be a problem presented by the medical coders. In a similar study, one medical coder estimated that discharge notes were missing in $80 \%$ of charts (Tang et al., 2017). Similarly, the information required in the surgery report was already established (ACSS, 2011), but lack of information in the surgery report continued to be a problem. Moreover, Conselho Nacional de Auditoria e Qualidade - National Council for Audit and Quality - also made recommendations about the necessary information for surgery health records (Conselho Nacional de Auditoria e Qualidade, 2016).

The use of abbreviations and acronyms was another problem highlighted by medical coders, which was also reported in a Canadian study involving medical coders (Lucyk et al., 2017). It has been observed that abbreviations 
should be avoided to improve coding accuracy (Naran et al., 2014); medical coders are not always familiar with the large number of abbreviations used (Farzandipour et al., 2010). In Portugal, medical coders have always struggled to code abbreviations and only ignored them when they could not understand them at all; the proof of this is that the three pages of the Portal da Codificação with lists of abbreviations and their meanings found over the years in health records were the most frequently consulted on this platform. Nowadays, the Portal da Codificação is unavailable, which also does not help to solve this problem. The Joint Commission (JC), a private entity of the United States of America (USA) that provides hospitals' accreditation, requires that institutions use "standardised" abbreviations, advising the development of an approach to exclude possible ambiguities in use of the abbreviations (Joint Commission International, 2018). In Portugal, national health entities could promote a national index of abbreviations and acronyms, to which health professionals should adhere.

\section{Variability in health records}

In the view of the participants the quality of the health records varied among institutions and specialties, which may have been influenced by different perceptions of the importance of health records. The specificity of the information recorded was considered an important characteristic for clinical coding, but we concluded that the lack of specificity in the diagnosis is common. In our study, this lack of specificity was considered a consequence of the lack of assertiveness of some physicians who, instead of interpreting exam reports and making a diagnosis, only transcribed exam reports. In another study performed with medical coders, the lack of specificity in physician documentation was considered a major barrier to coding (Tang et al., 2017). This lack of specificity may result in greater difficulty in identifying the main diagnosis, or even in the impossibility of coding a diagnosis, because it is not documented by the physician (O'Malley et al., 2005; Tang et al., 2017). Despite the identified problems and the variability in health records, participants argued that there was a continuous improvement in their quality. This improvement may partly explain the increase of the number of coded secondary diagnoses, verified in Portuguese hospitals (Barros and Braun, 2017; Freitas et al., 2014).

\section{PHRs compared to EHRs}

Regarding format, and as described in the literature, it was also argued that the use of EHRs, allowing more structured data and eliminating the illegibility problem present in PHRs, has improved the quality of healthcare, the coding activity and the population health itself (Klein et al., 2012; Morrison et al., 2014; Robertson et al., 2015; Tang et al., 2017; Van Der Bij et al., 2017; Williams et al., 2017). On the other hand, one of the disadvantages attributed to the EHR is that it allows "copy \& paste" of previous records, duplicating information and perpetuating possible errors. This functionality has appeared in the literature related to saving time, increasing the efficiency of the process (Al Hadidi et al., 2017; Hartzband and Groopman, 2008; Heiman et al., 2014; Hirschtick, 2006; March et al., 2016; Shoolin et al., 2013). Transcriptions should be made in a conscious and responsible way by health professionals, taking advantage of the positive points for which "copy \& paste" was created. This problem was also already addressed by AHIMA and JC, both highlighting the need to train and to educate on proper use of "copy \& paste", to monitor its use, to evaluate associated errors and to institute corrective action as needed (AHIMA, 2014; Joint Commission International, 2015). In our study, participants also referred the drawback of EHRs not allowing explanatory drawings.

\section{Possible solutions to problems with health records}

Although the identified problems were similar to those already known in other countries (Bajaj et al., 2007; DeAlmeida et al., 2014; Haghighi et al., 2014; Lucyk et al., 2017; O'Malley et al., 2005; Tang et al., 2017), there is still a lack of investment in the necessary policies in Portugal. However, some institutions are starting to act in situ. The existence of official guidelines (with adequate monitoring/audits) to standardise the structure and content of health records is of major importance, complemented with the easy access and wide acceptance from medical doctors, with the ultimate aim of improving health record quality. The development of guidelines for documentation and clinical coding involving both medical coders and medical doctors, among other professionals, would be important (Resslar et al., 2018). Another solution for some of these problems could be the use of Systematized Nomenclature of Medicine - Clinical Terms (SNOMED-CT) in EHRs, a terminology that allows recording information in a standardised way, facilitating the clinical coding (SNOMED International, 2018; Spencer, 2016).

Audits of health records are also important to improve the practice of health professionals and to improve health records (Dinescu et al., 2011; Ivers et al., 2012; Klein et al., 2012; Thomas et al., 2008). Participants described that, in the past, internal reviews of health records were performed for educational purposes and contributed to the improvement of health records. Despite mandatory quarterly audits (Diário da República, 2013), participants described a decrease in the volume of these internal reviews, which might compromise the audits purposes. In other countries, such as USA and Australia, clinical documentation improvement programmes, which include people, processes and technology, were implemented to facilitate the accurate representation of a patient's clinical status, and this also allows that the recorded information fits the medical coders' needs (AHIMA, 2018; Breuer and Arquilla, 2011; Shepheard, 2018; Towers, 2013). Similarly, in Spain, a career of specialist in admission and clinical documentation was created in 2001, being responsible for clinical documentation and also clinical coding (Martín-Vegue, 2000). These careers do not exist in Portugal. The education and training for physicians on how to document in the 
health records could be another important point to solve these problems. In fact, documentation tends to be more complete after the training of health professionals (Rowlands et al., 2016; Spellberg et al., 2013; Van Der Bij et al., 2017). The accreditation of hospitals is another factor that might improve health records as well as the quality of healthcare (Alkhenizan and Shaw, 2011; Schmaltz et al., 2011). In Portugal, the accreditation and certification of healthcare services are behindhand (SNS, 2017), which also does not help to solve the problems identified in this study.

\section{Limitations}

The sample of medical coders was constructed out of convenience, consisting of medical coders who participated voluntarily in the study and who worked in only four hospitals in the north of the country. Participants could not be selected randomly due to the low number of medical coders who showed willingness to participate, which may have produced a bias. Moreover, we were unable to collect data until saturation. Another limitation is the possibility of some competitiveness between medical coders belonging to different hospitals, compromising the exposure of the whole reality of each institution. This is related to a known limitation of focus groups (Morgan, 1996; Smithson, 2000). Some people are uncomfortable giving their opinion, a problem that can only be solved through individual interviews.

\section{Conclusion}

According to our participants, health professionals do not seem to be sensitised to the importance of health records in the coding activity. Incomplete, unclear and non-specific documentation in the health records not only hindered the coding process but also worsened the communication across health professionals. Moreover, these problems may have a negative impact for different coded data purposes. The use of more concise standards in the health records would result in higher quality records, contributing to the improvement in the coding activity and in the provision of care. There is a need for external audits to ensure that guidelines are followed, promoting the awareness of all health professionals to the importance of health records. Future research should be performed in order to gauge the degree of impact in hospital reimbursement, in clinical and health services research, as well as in health policy.

\section{Acknowledgements}

The authors would like to thank the focus group participants and to the Project NanoSTIMA (NORTE-01-0145-FEDER-000016).

\section{Declaration of conflicting interests}

The authors declared no potential conflicts of interest with respect to the research, authorship, and/or publication of this article.

\section{Funding}

The authors disclosed receipt of the following financial support for the research, authorship, and/or publication of this article: The project is financed by the North Portugal Regional Operational Programme (NORTE 2020), under the PORTUGAL 2020 Partnership Agreement, and through the European Regional Development Fund (ERDF).

\section{ORCID iDs}

Vera Alonso, MSc D https://orcid.org/0000-0002-0728-3192

Alberto Freitas, PhD (D) https://orcid.org/0000-0003-2113-9653

\section{References}

ACSS (2011) Manual SIGIC - Volume III - Área Clínica. Available at: http://www.acss.min-saude.pt//wp-content/uploads/ 2016/12/UCGIC-CM-20110511-Vol-III-Area-Clinica.pdf (accessed 17 October 2018).

AHIMA (2014) Appropriate use of the copy and paste functionality in electronic health records. Available at: https:// bok. ahima.org/PdfView?oid=300306 (accessed 28 June 2018).

AHIMA (2018) Clinical documentation improvement. Available at: http://www.ahima.org/topics/cdi (accessed 28 June 2018).

Al Hadidi S, Upadhaya S, Shastri R, et al. (2017) Use of dictation as a tool to decrease documentation errors in electronic health records. Journal of Community Hospital Internal Medicine Perspectives 7(5): 282-286.

Alkhenizan A and Shaw C (2011) Impact of accreditation on the quality of healthcare services: a systematic review of the literature. Annals of Saudi Medicine 31(4): 407-416.

Ayatollahi H, Mirani N and Haghani H (2014) Electronic health records: What are the most important barriers? Perspectives in Health Information Management 11(Fall): 1c.

Bajaj Y, Crabtree J and Tucker AG (2007) Clinical coding: How accurately is it done? Clinical Governance: An International Journal 12(3): 159-169.

Bardin L (2011) Análise de Conteúdo. 4 edicao. Lisboa: EDICOES 70.

Barros P and Braun G (2017) Upcoding in a national healthcare service: the evidence from Portugal. Health Economics 26(5): 600-618.

Breuer S and Arquilla V (2011) Clinical documentation improvement: focus on quality. Healthcare Financial Management 65(8): 84-86.

Conselho Nacional de Auditoria e Qualidade (2016) Boas práticas de registos clínicos em cirurgia. Available at: http://ordemdos medicos.pt/wp-content/uploads/2017/09/CM_20160217_ Registos_cli769nicos_em_cirurgia_v3F.pdf (accessed 16 October 2018).

DeAlmeida DR, Watzlaf VJ, Anania-Firouzan P, et al. (2014) Evaluation of inpatient clinical documentation readiness for ICD-10-CM. Perspectives in Health Information Management 11(Winter): $1 \mathrm{~h}$.

Diário da República (2013) Despacho no 2784/2013. Diário da República: II série, $\mathrm{n}^{\mathrm{o}} 36$. Available at: https://dre.pt/applica tion/conteudo/1675776 (accessed 17 April 2018).

Dinescu A, Fernandez H, Ross JS, et al. (2011) Audit and feedback: an intervention to improve discharge summary completion. Journal of Hospital Medicine 6(1): 28-32.

Farzandipour M, Sheikhtaheri A and Sadoughi F (2010) Effective factors on accuracy of principal diagnosis coding based on 
International Classification of Diseases, the 10th revision (ICD-10). International Journal of Information Management 30(1): 78-84.

Freitas A, Silva-Costa T, Lopes F, et al. (2012) Factors influencing hospital high length of stay outliers. BMC Health Services Research 12: 265.

Freitas A, Gaspar J, Rocha N, et al. (2014) Quality in hospital administrative databases. Applied Mathematics \& Information Sciences 8(1L): 1-6.

Haghighi MHH, Dehghani M, Teshizi SH, et al. (2014) Impact of documentation errors on accuracy of cause of death coding in an educational hospital in Southern Iran. Health Information Management Journal 43(2): 35-42.

Hartzband P and Groopman J (2008) Off the record - avoiding the pitfalls of going electronic. The New England Journal of Medicine 358(16): 1656-1658.

Heiman HL, Rasminsky S, Bierman JA, et al. (2014) Medical students' observations, practices, and attitudes regarding electronic health record documentation. Teaching and Learning in Medicine 26(1): 49-55.

Hirschtick E (2006) Copy-and-paste. Journal of the American Medical Association 295(20): 2335-2336.

INE (2017) Portal do instituto nacional de estatística. Available at: https://www.ine.pt/xportal/xmain?xpid=INE\&xpgid=ine indicadores\&indOcorrCod $=0008121 \&$ contexto $=$ bd\&se 1 $\mathrm{Tab}=\mathrm{tab} 2$ (accessed 4 October 2018).

Ivers N, Jamtvedt G, Flottorp S, et al. (2012) Audit and feedback: effects on professional practice and healthcare outcomes. The Cochrane Database of Systematic Reviews 6: CD000259.

Joint Commission International (2015) Preventing copy-and-paste errors in EHRs. Available at: https://www.jointcommission. org/assets/1/23/Quick_Safety_Issue_10.pdf (accessed 28 June 2018).

Joint Commission International (2018) Use of codes, symbols, and abbreviations. Available at: https://www.jointcommissio ninternational.org/use-of-codes-symbols-and-abbreviations/ (accessed 28 June 2018).

Klein D, Staples J, Pittman C, et al. (2012) Using electronic clinical practice audits as needs assessment to produce effective continuing medical education programming. Medical Teacher 34(2): 151-154.

Kurusz S (2015) Successfully navigation the transition to ICD-10 terminology. Bulletin of the American College of Surgeons 100(12): 44-46.

Lucyk K, Tang K and Quan H (2017) Barriers to data quality resulting from the process of coding health information to administrative data: a qualitative study. BMC Health Services Research 17(1): 766.

March CA, Scholl G, Dversdal RK, et al. (2016) Use of electronic health record simulation to understand the accuracy of intern progress notes. Journal of Graduate Medical Education 8(2): 237-240.

Martín-Vegue AR (2000) La categoría de médico de admissión y documentación clínica: Una apuesta de futuro. Papeles Méd$i \cos$ 9(1): 32-38.

McKenzie K, Walker S, Dixon-Lee C, et al. (2004) Clinical coding internationally: a comparison of the coding workforce in Australia, America, Canada and England. In: 14th
International Federation of Health Records Congress, Washington, 2004.

Miller RH and Sim I (2004) Physicians' use of electronic medical records: barriers and solutions. Health Affairs 23(2): 116-126.

Morgan DL (1996) Focus groups. Annual Review of Sociology 22: 129-152.

Morrison Z, Fernando B, Kalra D, et al. (2014) National evaluation of the benefits and risks of greater structuring and coding of the electronic health record: exploratory qualitative investigation. Journal of the American Medical Informatics Association 21(3): 492-500.

Naran S, Hudovsky A, Antscherl J, et al. (2014) Audit of accuracy of clinical coding in oral surgery. British Journal of Oral Maxillofacial Surgery 52(8): 735-739.

O’Malley KJ, Cook KF, Price MD, et al. (2005) Measuring diagnoses: ICD code accuracy. Health Services Research 40(5 Pt 2): 1620-139.

Pinho I, Santos JV, Dinis-Ribeiro M, et al. (2015) Burden of digestive diseases in Portugal. European Journal of Gastroenterology \& Hepatology 27(3): 279-289.

Resslar MA, Ivanitskaya LV, Perez MA, et al. (2018) Sources of variability in hospital administrative data: clinical coding of postoperative ileus. Health Information Management Journal 1: 1833358318781106.

Robertson ARR, Fernando B, Morrison Z, et al. (2015) Structuring and coding in health care records: a qualitative analysis using diabetes as a case study. Journal of Innovation in Health Informatics 22(2): 275-283.

Rowlands S, Coverdale S and Callen J (2016) Documentation of clinical care in hospital patients' medical records: a qualitative study of medical students' perspectives on clinical documentation education. Health Information Management Journal 45(3): 99-106.

Santos JV, Pereira J, Pinto R, et al. (2017) Atrial fibrillation as an ischemic stroke clinical and economic burden modifier: a 15year nationwide study. Value in Health 20(8): 1083-1091.

Santos JV, Oliveira A, Costa-Pereira A, et al. (2016) Burden of burns in Portugal, 2000-2013: a clinical and economic analysis of 26,447 hospitalisations. Burns 42(4): 891-900.

Santos S, Murphy G, Baxter K, et al. (2008) Organisational factors affecting the quality of hospital clinical coding. Health Information Management Journal 37(1): 25-37.

Schmaltz SP, Williams SC, Chassin MR, et al. (2011) Hospital performance trends on national quality measures and the association with Joint Commission accreditation. Journal of Hospital Medicine 6(8): 454-461.

Shepheard J (2018) What do we really want from clinical documentation improvement programs? Health Information Management Journal 47(1): 3-5.

Shoolin J, Ozeran L, Hamann C, et al. (2013) Association of Medical Directors of Information Systems consensus on inpatient electronic health record documentation. Applied Clinical Informatics 4(2): 293-303.

Smithson J (2000) Using and analysing focus groups: limitations and possibilities. International Journal of Social Research Methodology 3(2): 103-119.

SNOMED International (2018) Why SNOMED CT? Available at: https://www.snomed.org/snomed-ct/why-snomed-ct (accessed 20 November 2018). 
SNS (2017) Programa de Acreditação. Available at: https://www. sns.gov.pt/noticias/2017/01/06/programa-de-acreditacao/ (accessed 28 June 2018).

Spencer SA (2016) Future of clinical coding. BMJ 353: 2875.

Sousa-Pinto B, Cardoso-Fernandes A, Araújo L, et al. (2018) Clinical and economic burden of hospitalizations with registration of penicillin allergy. Annals of Allergy, Asthma \& Immunology 120(2): 190-194.e2.

Southern DA, Hall M, White DE, et al. (2016) Opportunities and challenges for quality and safety applications in ICD-11: an international survey of users of coded health data. International Journal for Quality in Health Care 28(1): 129-135.

Spellberg B, Harrington D, Black S, et al. (2013) Capturing the diagnosis: an internal medicine education program to improve documentation. The American Journal of Medicine 126(8): 739-743.e1.

Tang KL, Lucyk K and Quan H (2017) Coder perspectives on physician-related barriers to producing high-quality administrative data: a qualitative study. Canadian Medical Association Journal Open 5(3): E617-E622.
Tatham A (2008) The increasing importance of clinical coding. British Journal of Hospital Medicine 69(7): 372-373.

Thomas AN, Boxall EM, Laha SK, et al. (2008) An educational and audit tool to reduce prescribing error in intensive care. Quality \& Safety in Health Care 17(5): 360-363.

Tong A, Sainsbury P and Craig J (2007) Consolidated criterio for reporting qualitative research (COREQ): a 32-item checklist for interviews and focus group. International Journal of Qualitative in Health Care 19(6): 349-357.

Towers AL (2013) Clinical documentation improvement - a physician perspective: insider tips for getting physician participation in CDI programs. Journal of AHIMA 84(7): 34-41.

Van Der Bij S, Khan N, Ten Veen P, et al. (2017) Improving the quality of EHR recording in primary care: a data quality feedback tool. Journal of the American Medical Informatics Association 24(1): 81-87.

Williams R, Kontopantelis E, Buchan I, et al. (2017) Clinical code set engineering for reusing EHR data for research: a review. Journal of Biomedical Informatics 70: 1-13.

\section{Appendix I}

Table IA. Consolidated criteria for reporting qualitative studies (COREQ): 32-item checklist.

No. of items Guide questions/description

\section{Domain I: Research team and reflexivity}

Personal Characteristics

I. Interviewer/facilitator Which author/s conducted the focus groups?

2. Credentials What were the researcher's credentials?

3. Occupation

4. Gender

What was their occupation at the time of the study?

5. Experience and training

Was the researcher male or female?

What experience or training did the research have?

\footnotetext{
Relationship with participants
6. Relationship established of the interviewer characteristics
Was a relationship established prior to study commencement?
What did the participants know about the researcher?
What characteristics were reported about

7. Participant knowledge

8. Interviewer

Domain 2: Study design

Theoretical framework

9. Methodological orientation and theory

What methodological orientation was stated to underpin the study?
}

Vera Alonso (VA), Joana Ferreira (JF) and Isabel Lema (IL) VA - MSc; João Vasco Santos (JVS) - MD; Marta Pinto (MP) - PhD; JF - MSc; IL - BSc; Fernando Lopes (FL) MD; Alberto Freitas (AF) - PhD

VA - research fellow; JVS - medical doctor; MP - senior researcher; JF - research fellow; IL - research assistant; $\mathrm{FL}$ - coding educator; $\mathrm{AF}$ - senior researcher

VA - female; JVS - male; MP - female; JF - female; IL female; $\mathrm{FL}$ - male; $\mathrm{AF}$ - male

JVS - experience in research reusing the coded data and medical background; MP - qualitative researcher with extensive experience of interview and focus group research; IL - experience in research reusing the coded data; $\mathrm{FL}$ - extensive experience in clinical coding; AF extensive experience in research reusing the coded data

No

Occupations and reasons for doing the research

Some researchers were integrated in a project that funded this research. Reasons for the research topic

Thematic analysis 
Table IA. (continued)
No. of items
Guide questions/description

\section{Participant selection}

I0. Sampling

II. Method of approach

12. Sample size

13. Non-participation
How were participants selected?

How were participants approached?

How many participants were in the study?

How many people refused to participate or dropped out? Reasons?

\section{Setting of data collection \\ 15. Presence of non-participants \\ 16. Description of sample}

\section{Data collection}

17. Interview guide

18. Repeat interviews

19. Audio/visual recording

20. Field notes

21. Duration

22. Data saturation

23. Transcripts returned

\section{Domain 3: Ana}

24. Number of data coders?

25. Description of the coding tree

26. Derivation of themes

\section{Software}

28. Participant checking

\section{Reporting}

29. Quotations presented

30. Data and findings consistent

3I. Clarity of major themes

32. Clarity of minor themes
Where was the data collected?

Was anyone else present besides the participants and researchers?

What are the important characteristics of the sample?

Were questions, prompts, guides provided by the authors? Was it pilot tested?

Were repeat interviews carried out? If yes, how many?

Did the research use audio or visual recording to collect the data?

Were field notes made during and/or after the interview or focus group?

What was the duration of the interviews or focus groups?

Was data saturation discussed?

Were transcripts returned to participants for comment and/or correction?

How many data coders coded the data?

Did authors provide a description of the coding tree?

Were themes identified in advance or derived from the data?

What software, if applicable, was used to manage the data?

Did participants provide feedback on the findings?

Were participant quotations presented to illustrate the themes/findings? Was each quotation identified?

Was there consistency between the data presented and the findings?

Were major themes clearly presented in the Yes findings?

Is there a description of diverse cases or discussion of minor themes?

No

No

No Yes

Yes

Yes

Yes
Convenience sampling

Email

Ten participants

One of the medical coders was not able to attend any of the sessions, due to schedule incompatibility In one of the sessions of each group, there was a lack of one participant, due to last minute unexpected

Presential - Faculty of Medicine of the University of Porto

Medical coders with some experience in clinical coding ((See characteristics of the focus groups' participants in Table I)

Yes, an interview guide with semi-structured questions was used; the content of the draft interview guide was discussed with the project group; no, it was not pilot tested

Audio

Yes, during the focus groups

One hour and 15 minutes and one hour and 50 minutes

No, due to the low number of coders who showed availability

One, VA. The coded data are after approved by all the other authors

Some themes were identified in advance according to the aim of the study, and some themes derived from the data

Not applicable

Yes. We held a meeting with the participants to present the results and they have the opportunity to provide feedback on the findings 